\title{
REDUÇÃO DE PERDAS DE MATERIAIS NA ELEVAÇÃO DE ALVENARIAS DE UM EDIFÍCIO MULTIPAVIMENTOS POR MEIO DA APLIÇAÇÃO DA PRODUÇÃO MAIS LIMPA
}

\author{
Janaina Brum Gularte ${ }^{1}$ \\ Adalberto Pandolfo ${ }^{2}$ \\ Ritielli Berticelli ${ }^{3}$
}

\section{RESUMO}

O artigo tem por objetivo a introdução de elementos norteadores do programa de Produção mais Limpa, em atividade que conhecidamente costuma ser grande geradora de perdas: elevação de alvenaria. Por meio de um estudo de caso focado nesta atividade, durante a produção de um edifício multipavimentos, buscou-se gerar oportunidades de melhoria com a abordagem de redução na fonte para minimização de perdas de recursos materiais e geração de resíduos. A metodologia adotada fundamentou-se nas principais etapas propostas no programa de Produção mais Limpa, do CNTL (2007). Assim, foi possível verificar as causas das ocorrências de perdas, identificar as oportunidades de Produção mais Limpa, realizando o levantamento dos gastos para implementação, elaborando um plano de implementação de forma a auxiliar as pessoas diretamente relacionadas com as mudanças propostas, no entendimento das necessidades e respectivas ações. $\mathrm{Na}$ atividade selecionada para o estudo foi possível verificar as causas das ocorrências de resíduos, identificar as opções de oportunidades de Produção mais Limpa, propor modelos de avaliações técnica, ambiental e econômica e elaborar um plano de implementação. Os resultados dos acompanhamentos da execução da atividade apontaram que as causas poderiam estar relacionadas com a qualidade duvidosa da cerâmica utilizada, movimentações de materiais desnecessárias, ausência de estudo de layout do pavimento em produção, entre outros. As opções de melhoria apresentadas revelaram que para reduzir os resíduos, não são necessários altos investimentos, bastando adaptações pontuais nos serviços já consolidados. A implementação das proposições de melhoria é totalmente viável a quaisquer canteiros de obras semelhantes ao estudado.

Palavras-chave: Produção de edifícios; Minimização de perdas; Construção sustentável; Resíduos de construção civil.

\footnotetext{
${ }^{1}$ Mestre no Programa de Pós-Graduação em Engenharia Civil e Ambiental da Universidade de Passo Fundo (UPF). E-mail: jbgularte@hotmail.com

2 Doutor em Engenharia de Produção. Professor do Programa de Pós-Graduação em Engenharia Civil e Ambiental da Universidade de Passo Fundo. E-mail: Adalberto.pandolfo@gmail.com

3 Doutora em Engenharia. Professora na Universidade do Estado de Mato Grosso. E-mail: ritiberticelli@yahoo.com.br
} 


\title{
REDUCTION OF LOSSES OF MATERIALS IN THE ELEVATION OF MASONRY OF A BUILDING MULTIPAVIMENTOS BY MEANS OF THE APPLICATION OF THE CLEANER PRODUCTION
}

\begin{abstract}
This paper aims to introduce the guiding elements of the Cleaner Production program in an activity well-known as a large generator of losses: masonry elevation. Through a case study focused on this activity during the production of a multi-floor building, it was sought to generate improvement opportunities with the reduction at the source approach for losses minimization of material resources and waste generation. The adopted methodology was based on the main steps proposed by the Cleaner Production program of the National Center of Cleaner Technologies - CNTL (2007). Thus, it was possible to verify the causes of loss events, to identify cleaner production opportunities, to propose an assessment model for technical, environmental and economic aspects and to prepare an implementation plan in order to support people directly involved to the proposed changes in understanding the needs and the respective actions. In the activity selected for the study, it was possible to verify the causes of waste occurrences, identify options for Cleaner Production opportunities, propose models for technical, environmental and economic assessments and prepare an implementation plan. The results of the monitoring of the execution of the activity indicated that the causes could be related to the doubtful quality of the ceramic used, unnecessary material movements, absence of a study of the pavement layout in production, among others. The improvement options presented revealed that to reduce waste, high investments are not necessary, just occasional adaptations in the services already consolidated. The implementation of the improvement proposals is fully feasible at any construction sites similar to the one studied.
\end{abstract}

Keywords: Production buildings; Loss minimization; Sustainable construction; Construction waste.

\section{1- INTRODUÇÃO}

O setor da construção civil representa uma das atividades mais importantes para o desenvolvimento do país (SOUZA, 2005). No ano de 2019, a construção civil foi o segmento que registrou o maior crescimento, com 1,3\% de expansão, acumulando 4,4\%. Combinados, esses indicadores reforçam o que temos defendido há muito tempo: quando a construção civil vai bem, a economia brasileira reage rápido (CBIC, 2020).

A indústria da construção também possui importância expressiva quando comparada às demais indústrias, pelos efeitos causados ao meio ambiente. A etapa de construção, no ciclo de vida de um empreendimento, responde por uma parcela significativa dos impactos causados pela construção civil no meio ambiente (CARDOSO; ARAÚJO, 2006). Segundo Pinto e Gonzales (2005), a construção civil continua como uma das maiores atividades 
geradoras de impactos ambientais negativos, tanto pelo consumo de recursos naturais, quanto pela modificação da paisagem, ou ainda, pela geração de resíduos.

$\mathrm{Na}$ execução de uma obra se verifica boa parte dos impactos causados pela construção civil, o que justifica a necessidade de se conhecerem as intensidades desses impactos, pois, uma vez priorizados, podem ser reduzidos ou eliminados por meio de ações específicas (CARDOSO; ARAÚJO, 2004; MACHADO, 2006).

Segundo Suzer (2015), a indústria da construção é responsável pelo consumo de $40 \%$ dos recursos globais, $12 \%$ das reservas de água potável, $55 \%$ de produtos de madeira, $40 \%$ de matérias-primas, gerando 45 a $65 \%$ dos resíduos produzidos e emitindo $48 \%$ dos gases prejudiciais de efeito estufa, poluindo ar e água, ameaçando o esgotamento dos recursos naturais e promovendo o aquecimento global.

A crescente demanda do mercado imobiliário de edifícios residenciais nos últimos anos instigou diversas pesquisas na área, tanto para redução de perdas de materiais, como no aumento da produtividade nos canteiros de obra. Para Santos et al. (1996), com frequência o conceito de perdas é associado aos desperdícios de materiais, no entanto, segundo os autores, estas devem ser entendidas como qualquer ineficiência que se reflita no uso de equipamentos, materiais e mão-de-obra, em quantidades superiores ao necessário, gerando custos adicionais e não agregando valor ao produto final, no caso, a edificação.

Sobre os resíduos da construção, John e Agopyan (2008) sugerem algumas medidas, como por exemplo, as mudanças tecnológicas para reduzir as perdas, melhoria da qualidade da construção, seleção adequada dos materiais, capacitação dos recursos humanos, melhoria das condições de estoque e transporte, incentivo para que os proprietários realizem modificações nas edificações e não demolições, taxação sobre a geração de resíduos e campanhas educativas. A maioria dessas medidas sugere o aproveitamento eficiente de recursos. Dias (2006) destaca a necessidade de se buscarem maiores níveis de qualidade e eficiência nos processos por meio da racionalização da produção. A construção sustentável objetiva desenvolver modelos e ferramentas que permitam ao setor da construção enfrentar e propor soluções aos principais problemas ambientais (SEVERO; SOUSA, 2016).

Nesse contexto surge a proposta metodológica da Produção mais Limpa $(P+L)$, que segundo a Organização das Nações Unidas para o Desenvolvimento Industrial e o 
Programa das Nações Unidas para o Meio Ambiente (UNIDO/UNEP, 1995), é um programa de aplicação contínua de uma estratégia ambiental preventiva e integrada a processos produtivos, nos produtos e nos serviços, para reduzir os riscos relevantes aos seres humanos e ao meio ambiente. Em vez de apenas tratar adequadamente os resíduos, a Produção mais Limpa propõe em primeiro lugar a não geração de resíduos por meio de ajustes no processo produtivo, e na impossibilidade, a redução da sua geração, reutilização, reciclagem interna e externa, e, por fim, se não for possível todas as possibilidades antecessoras, a disposição adequada dos resíduos.

Assim, a proposta da Produção mais Limpa vai ao encontro das legislações e diretrizes vigentes no país sob o ponto de vista dos resíduos, como a Política Nacional de Resíduos Sólidos - PNRS, sob a Lei Federal № 12.305 (BRASIL, 2010) e a Resolução CONAMA no 307 (BRASIL, 2002). Mas, como é possível a introduzir a metodologia de Produção mais Limpa nas atividades produtivas de edifícios multipavimentos?

Visando a manutenção do meio ambiente e o emprego eficiente de recursos, a presente pesquisa propõe opções de melhorias nas atividades de produção do subsetor edificações, inserido no setor de construção civil, por meio da proposta de implementação de um programa de Produção mais Limpa.

\section{2- PRODUÇÃO MAIS LIMPA X CONSTRUÇÃO CIVIL}

O fluxo de geração de resíduos é observado em todo ciclo de vida de uma construção, desde a sua produção, uso/manutenção até a demolição. Segundo Su et al. (2012), durante a fase de uso/manutenção raramente os resíduos de construção civil - RCC são gerados, a menos que ocorram reformas. Para Wu et al. (2014), é possível classificar três atividades de geração de resíduos primários: a construção de novos edifícios, a demolição de edifícios, e as obras de infraestrutura.

Segundo Wu et al. (2014), durante a fase de construção de novos edifícios as perdas de materiais por resíduos são consideradas inevitáveis. Para os autores, as causas típicas nesta fase incluem, entre outros, o método de construção, tamanho do projeto, tipo de construção, forma de armazenamento de material, erro humano e problemas técnicos. Pesquisas realizadas pelos autores indicam que, na prática, os empreiteiros geralmente assumem que a taxa de perdas é equivalente entre $1-10 \%$ dos materiais de construção 
comprados, e que a porcentagem específica é determinada por suas experiências anteriores derivadas de medição direta no local.

A grande quantidade em que os Resíduos de Construção Civil - RCC são gerados, seu elevado volume e a periculosidade à qual expõem o meio ambiente, tornando-se um problema ambiental. O manual de orientação para o plano de gerenciamento de resíduos sólidos proposto pelo Ministério do Meio Ambiente - MMA (BRASIL, 2012), revela, nos inventários de resíduos, a relação entre os resíduos de construção civil e os resíduos domiciliares, de dois para um. Para Buttler (2007), a presença dos resíduos das atividades de construção aumenta ainda mais, variando entre 54\% e 70\% da massa total de Resíduos Sólidos Urbanos - RSU.

Neste trabalho adotou-se a ferramenta de Produção mais Limpa por ser uma metodologia focada na gestão pela prevenção e controle de perdas, que proporciona às empresas uma economia significativa, já que objetiva a redução de desperdícios na fonte e reduz a poluição por meio da minimização de geração de seus resíduos, além de atender aos requisitos legais ambientais vigentes e aplicáveis e primar pela saúde e segurança dos profissionais envolvidos nas atividades produtivas.

O programa de Produção mais Limpa, segundo UNEP (1998), é a aplicação de uma estratégia técnica, econômica e ambiental integrada aos processos e produtos da organização, com o objetivo de aumentar a eficiência quanto ao uso de matérias-primas, água e energia, bem como por meio da não geração, minimização ou reciclagem dos resíduos e emissões geradas, inserindo benefícios ao ambiente, economia e saúde ocupacional.

Considerando a variável ambiental em todos os níveis da empresa, a Produção mais Limpa, segundo o CNTL (2007b), relaciona as questões ambientais com benefícios econômicos para as empresas que a adotam e se comprometem com a sua continuidade. Ela se caracteriza por promover ações que são implementadas no ambiente empresarial afim de tornar o processo mais eficiente, gerando mais produtos e menos resíduos (CNTL, 2007b).

Entre as principais metas da Produção mais Limpa, segundo o CNTL (2007b), destacam-se: (i) a redução de custos de produção e aumento de eficiência e competitividade; (ii) a redução das infrações aos padrões ambientais previstos na legislação; (iii) a diminuição dos riscos de acidentes ambientais; (iv) a melhoria das 
condições de saúde e de segurança do trabalhador; (v) a melhoria da imagem da empresa junto a consumidores, fornecedores e poder público; (vi) a ampliação das perspectivas de mercado interno e externo; (vii) o acesso facilitado a linhas de financiamento; e (viii) a melhoria do relacionamento com os órgãos ambientais, com a mídia e com a comunidade.

Segundo Markusson (2011), a Produção mais Limpa motiva a inovação ambiental para a empresa, e a inovação é que reduz o impacto ambiental de um processo de fabricação ou de um produto, elevando potencialmente a competitividade e produtividade da empresa.

\section{3- MÉTODO DA PESQUISA}

\section{1- CARACTERIZAÇÃO DO OBJETO DE ESTUDO}

Localizado no Planalto Médio, na região norte do estado do Rio Grande do Sul, Brasil, o município de Passo Fundo, possui área territorial de 783,421 km2 e uma população estimada em 195.620 habitantes. A tendência à concentração da verticalização no centro urbano, incentivada pelo II Plano Diretor de Desenvolvimento Urbano - PDDU em 1984, bem como em sua última revisão o Plano Diretor de Desenvolvimento Integrado, de 2006, favoreceu o estímulo à construção e aos negócios imobiliários (SOBARZO, 2010). Desde então, diversas obras de edifícios comerciais e residenciais são inicializadas e finalizadas o ano inteiro, movimentando a economia da cidade.

A construção está localizada em uma região de elevada densidade populacional transitória, no centro da cidade de Passo Fundo-RS.

\section{2- PROCEDIMENTO METODOLÓGICO DESENVOLVIDO NA PESQUISA}

Conforme aponta Gil (2008), quanto aos procedimentos adotados a presente pesquisa configura-se como estudo de caso, pois envolve o estudo atividades executivas inseridas no processo da produção do edifício, de maneira que se permita o seu conhecimento detalhado.

As etapas do estudo de caso de caráter exploratório têm a finalidade de obter dados que possibilitem descrever os processos da obra do Edifício. Tais dados foram obtidos por meio da análise documental, reuniões com o engenheiro responsável pelo setor da 


\section{¿Unisul}

qualidade da construtora, equipe técnica da obra, executores das atividades em estudo e equipe de apoio, além da observação direta no canteiro de obra.

As observações diretas das atividades em execução no período da pesquisa foram do tipo observações formais e informais de coleta de dados com imagens, conforme indica Yin (2001), ao considerar que as observações formais podem ser verificadas por meio da incidência de certos tipos de comportamento, como reuniões e trabalhos de fábrica, e as observações informais validadas por registros fotográficos.

A Figura 1 apresenta o fluxograma contendo as etapas e fases (identificadas por "E" e "F", respectivamente) da pesquisa.

Figura 1 - Estrutura metodológica para o desenvolvimento da pesquisa.

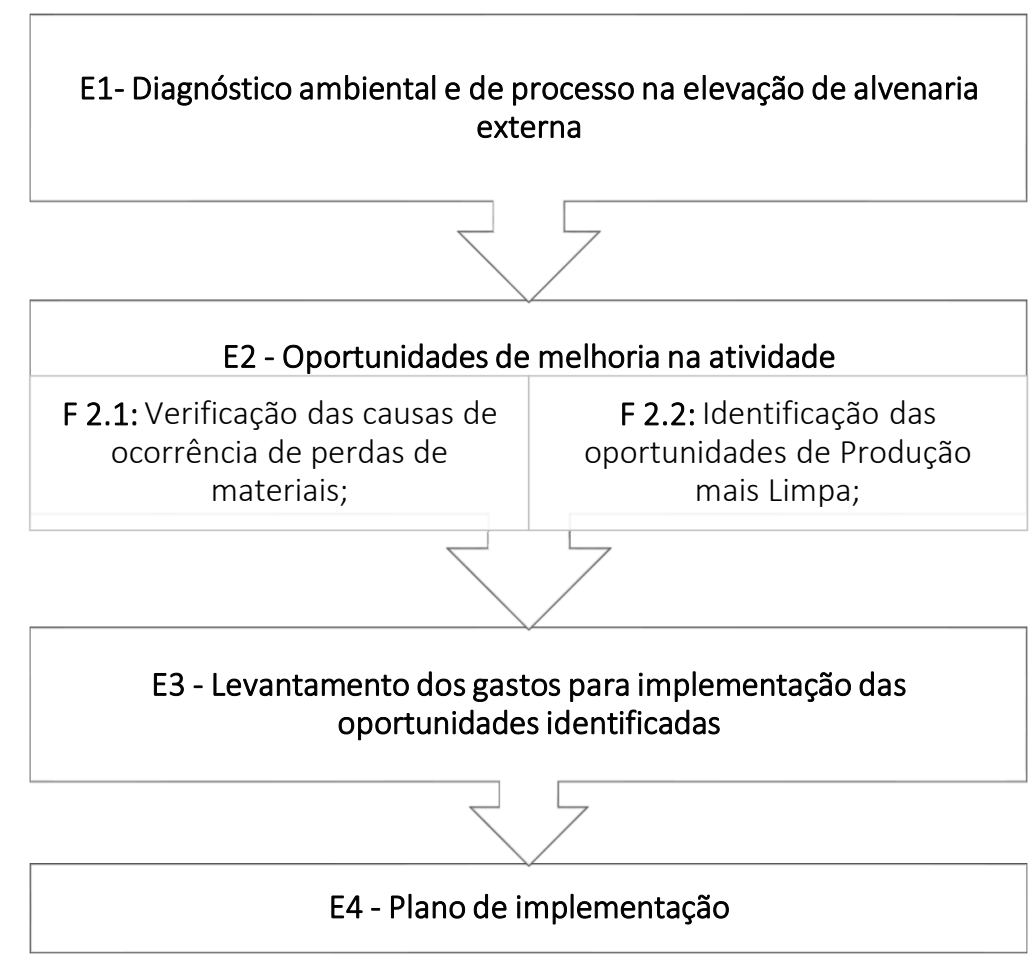

Fonte: Autores (2018).

A etapa 1 objetivou a apresentação dos dados de diagnóstico obtidos no acompanhamento das entradas e saídas da atividade, entre os pavimentos 10 e 11 . Sendo assim, buscou-se o conhecimento da obra em estudo, por meio de dados gerais da obra, localização, planejamento, recursos materiais e humanos, treinamentos e segurança do trabalho. As informações foram obtidas por meio de documentos disponibilizados pela 
Empresa, reuniões com a equipe técnica, e verificações in loco. A apresentação desses dados foi descrita na forma de texto e com o organograma da obra. Primeiramente foram listadas as etapas da produção dos pavimentos "tipo" do Edifício em estudo, e respectivas atividades, conforme informações obtidas no cronograma de longo prazo da obra. Em seguida foram evidenciados os principais recursos materiais e resíduos resultantes em cada uma dessas atividades. Logo, foram destacadas as atividades em execução no período da coleta de dados, e por último definidas as atividades mais representativas para o estudo de caso.

A etapa 2 foi elaborada considerando a condição observada no acompanhamento da etapa anterior. Para verificação das causas de ocorrência de perdas de materiais, foram realizadas análises críticas dessas observações. Nesta fase foi realizado o levantamento quantitativo das principais entradas e saídas das atividades em execução, no período estabelecido para a coleta de dados. Para isso, foi adotado o método de cálculo da taxa de geração, ou Generation Rate Calculation - GRC, que segundo Wu et al. (2014), é a metodologia mais usual para estimar quantidades de resíduos de construção e demolição, obtido por meio do conhecimento da sua produção por unidade, de uma atividade qualquer. Foram descritos os procedimentos para a coleta de dados e a análise de consumo de materiais versus geração de resíduos, além de apresentar como foram realizados ensaios em laboratório para obter a densidade média dos resíduos. Assim foi possível relacionar alguns fatores que poderiam contribuir com os índices de perdas de materiais. Baseado nesses resultados, e considerando os níveis de atuação e estratégias evidenciadas no fluxograma da geração de opções de Produção mais Limpa, do CNTL (2007a), foi possível propor uma lista de modificações na atividade em estudo, gerando oportunidades de melhoria.

Baseado nessa verificação foi possível gerar uma lista de modificações na produção do Edifício em estudo, considerando os níveis de atuação e as estratégias da Produção mais Limpa proposto pelo CNTL (2007a), evidenciados no fluxograma da geração de opções, conforme 
Figura 2.

Figura 2 - Fluxograma da geração de opções de Produção mais Limpa.

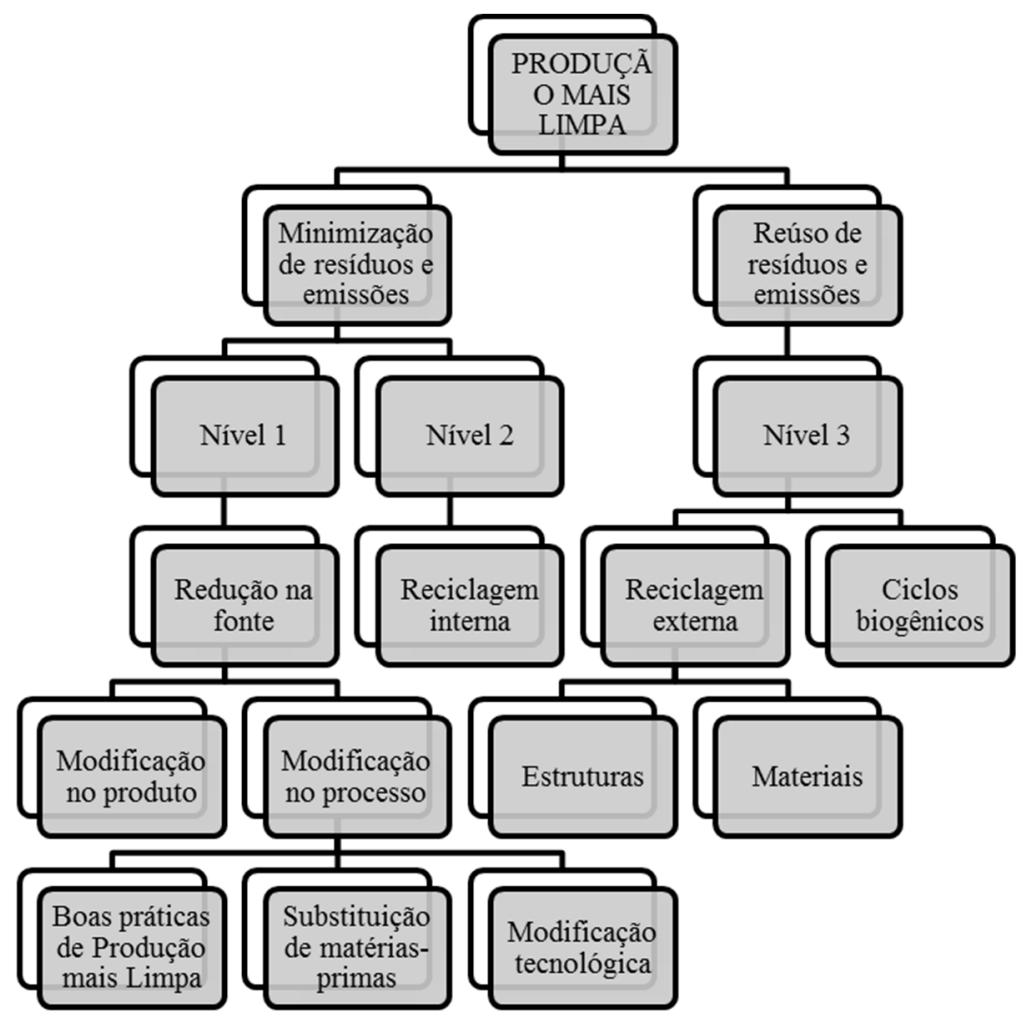

Fonte: Adaptado de CNTL (2007a).

Para etapa 3, foi realizado o levantamento de gastos para implementação das oportunidades destacadas, realizando orçamentos e calculando as quantidades e custos, conforme a necessidade da Obra, ou seja, para finalização dos últimos 4 pavimentos tipo que restavam executar.

A etapa 4 foi elaborada objetivando auxiliar no planejamento de implementação das oportunidades avaliadas. Uma ferramenta da qualidade foi adotada para facilitar o entendimento e a necessidade das mudanças propostas: o $5 \mathrm{~W} 2 \mathrm{H}$, uma sigla em inglês, referente aos seguintes questionamentos: What (o que será feito - etapas); Why (por que será feito - justificativa); Where (onde será feito - local); When (quando será feito - tempo); Who (por quem será feito - responsabilidade); How (como será feito - método); How much 


\section{¿Unisul}

(quanto custará fazer - custo) (MARSHALL JUNIOR et al., 2010). Para checagem, foi adotado um modelo de avaliação econômico e ambiental por metas de redução dos possíveis benefícios advindos com as oportunidades destacadas, servindo como indicadores de produção.

\section{4- RESULTADOS E DISCUSSÕES}

Quanto a geração de Resíduos de Construção Civil (RCC), segundo Bernardes et al. (2008), o município chegou a uma estimativa de geração de aproximadamente 0,55 kg.hab.dia-1 ${ }^{-1}$ o que caracteriza a proximidade dos valores dos Resíduos Sólidos Urbanos RSU (0,65 kg.hab.dia-1) gerados no município. Os autores classificaram esses RCCs de acordo com a Resolução CONAMA n 307 (BRASIL, 2002), como demonstrado na Figura 3, e obtiveram o valor expressivo de $94,5 \%$ de resíduo Classe A. Para as Classes B e C as quantidades foram bem inferiores, 3,10\% e 2,40\% respectivamente. Resíduos de Classe D não foram evidenciados na referida pesquisa.

Figura 3 - Tipos e percentuais de RCC coletados em Passo Fundo-RS

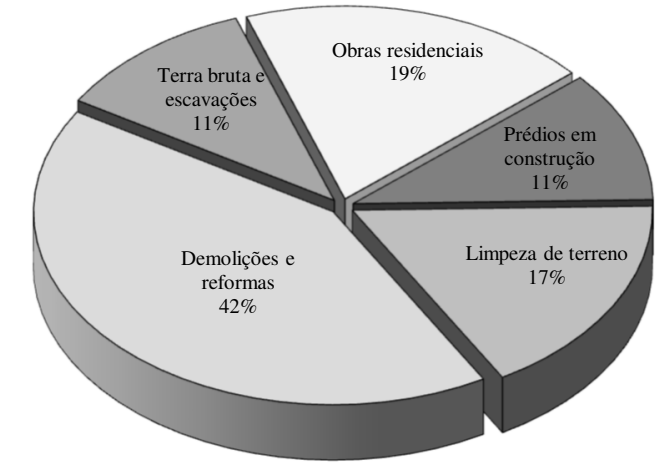

Fonte: Adaptado de Bernardes et al. (2008).

Conforme informações disponíveis na pesquisa de Bernardes et al. (2008), os resíduos provenientes de argamassas, tijolos e concreto são os mais representativos, chegando a 25,4\%, 24,5\% e 20,4\% respectivamente, para RCC provenientes de demolições e reformas e, 21,3\%, 27,8\% e 6,7\% respectivamente, para RCC provenientes das obras residenciais.

A construtora responsável pela obra objeto de estudo, denominada por "Empresa", já executou mais de cinquenta prédios comerciais e residenciais, superando duzentos mil 
metros quadrados de área construída, com conceito elevado no mercado onde atua. $\mathrm{A}$ Empresa já apresenta iniciativas de melhorias, como é o caso da obtenção da certificação com base na norma NBR ISO 9.001:2015, revalidada no período da coleta de dados da pesquisa, e também participa do Programa Brasileiro de Qualidade e Produtividade no Habitat (PBQP-H), com certificação no nível A, em uma escala em que "A" é a melhor nota, no Sistema de Avaliação da Conformidade (SIAC).

A Empresa tem conhecimento dos requisitos legais aplicáveis na temática de resíduos, e busca se adequar sempre que necessário, uma vez que, para garantir uma certificação nível A do PBQP-H e ISO 9001, é necessário que este assunto esteja de acordo a quaisquer requisitos legais pertinentes às suas atividades.

O edifício em produção é do tipo comercial e residencial, composto por 15 (quinze) pavimentos. Sua produção conta com uma equipe variando em torno de 50 (cinquenta) técnicos e profissionais experientes nesta tipologia de construção. A área de projeto contempla $6.223,66 \mathrm{~m}^{2}$ de construção, num terreno que possui $1.064,40 \mathrm{~m}^{2}$. Sua produção iniciou em outubro de 2013 e tem previsão de término em outubro de 2016, completando 3 (três) anos de obra. No período da pesquisa, a obra se encontrava na fase de produção dos pavimentos tipo, conforme verificado na Figura 4. As áreas destinadas às salas comerciais e garagens, eram utilizadas como espaços de apoio para recebimento, estocagem e processamento intermediário de recursos materiais, separação de resíduos (exceto os de "classe A", enviados ao fundo do terreno, para preenchimento de desnível), áreas de vivência, escritório e almoxarifado. 


\section{GESTÃO \& SUSTENTABILIDADE AMBIENTAL

\section{unisul}

Figura 4 - Fase de acompanhamento da obra: execução de pavimento tipo

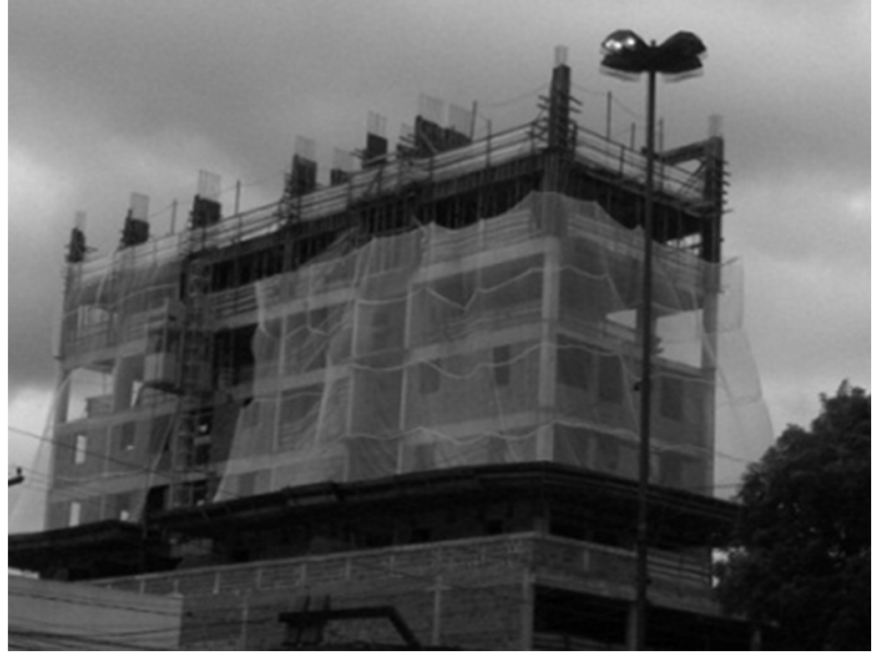

Fonte: Autores (2018).

A atividade foco de avaliação, execução de alvenaria externa, tem como entradas principais (recursos materiais): tijolos cerâmicos em variadas dimensões, argamassa industrializada, com retardador de cura de 36 e 72 horas (dependendo da necessidade). Como principais saídas (perdas por resíduos): argamassa residual, cascalhos de tijolos e resíduos particulados do tipo "Classe A", conforme Resolução CONAMA nํ 307 (BRASIL, 2002). A equipe de execução é constituída por várias duplas de pedreiros e serventes, contratados em acordo com a Consolidação das Leis do Trabalho - CLT, comissionados por produção.

Os itens de diagnóstico, necessários para gerar os custos materiais da atividade, tanto de entradas como saídas, bem como os custos aplicáveis, foram contabilizados e apresentados no

\section{Quadro 1.}

Os insumos (água e energia), embora citados no referido quadro, não foram quantificados nesta pesquisa. O mesmo ocorre para os custos relacionados à gestão de resíduos, que estão inseridos nas rotinas de trabalho das equipes de apoio (limpeza) da obra. A destinação externa dos resíduos não era praticada no período no qual foi realizado este levantamento, sendo depositados no fundo do terreno para preenchimento de desnível, e assim, não foram considerados nos custos finais. Não foram evidenciadas multas na obra, tão pouco na atividade em questão. Danos à imagem e reputação é um 


\section{GESTÃO \& SUSTENTABILIDADE AMBIENTAL}

\section{sunISUl}

item pertinente de avaliação, principalmente quando a empresa adota estratégias de marketing ambiental, contudo na presente pesquisa este item também não foi quantificado. Entretanto, optou-se por manter tais chamadas no

Quadro 1, de forma a servir de referência futura. A quantificação de particulados de tijolos e argamassa residual também não foi realizada, visto que não foi possível a segregação no momento da coleta.

Quadro 1 - Custos Input / Output (não produto) contabilizados para a elevação de alvenaria externa

\begin{tabular}{|c|c|c|c|c|c|c|c|c|c|}
\hline \multicolumn{2}{|c|}{ Transformação / situação } & Material & Quantidade & Unidade & $\begin{array}{c}\text { Custo } \\
\text { unitário }\end{array}$ & Custo total* & $\begin{array}{c}\text { Custos por } \\
\text { situação* }\end{array}$ & $\begin{array}{c}\text { Custos por } \\
\text { transformação* }\end{array}$ & $\begin{array}{c}\begin{array}{c}\text { Participação na } \\
\text { atividade** }\end{array} \\
\end{array}$ \\
\hline \multirow{5}{*}{$\frac{5}{5}$} & \multirow{3}{*}{$\uparrow$ Matéria- prima } & Tijolos 9x19x24 cm & 279 & $\mathrm{pç}$ & $\mathrm{R} \$ 0,76$ & $\mathrm{R} \$ 212,04$ & \multirow{3}{*}{$\mathrm{R} \$ 3.527,64$} & \multirow{5}{*}{$\mathrm{R} \$ 3.527,64$} & \multirow{5}{*}{$96,3 \%$} \\
\hline & & Tijolos $14 \times 19 \times 24 \mathrm{~cm}$ & 2610 & $\mathrm{pç}$ & $\mathrm{R} \$ 0,96$ & $\mathrm{R} \$ 2.505,60$ & & & \\
\hline & & $\begin{array}{c}\text { Argamassa } \\
\text { industrializada }\end{array}$ & 2,7 & $\mathrm{~m}^{3}$ & $\mathrm{R} \$ 300,00$ & $\mathrm{R} \$ 810,00$ & & & \\
\hline & \multirow{2}{*}{$\uparrow$ Insumos } & Água & $\begin{array}{c}\text { Não } \\
\text { contabilizado } \\
\end{array}$ & $\mathrm{m}^{3}$ & $\mathrm{R} \$ 0,00$ & Indefinido & \multirow{2}{*}{ Indefinido } & & \\
\hline & & Energia & $\begin{array}{c}\text { Não } \\
\text { contabilizado }\end{array}$ & $\mathrm{kw} / \mathrm{h}$ & $\mathrm{R} \$ 0,00$ & Indefinido & & & \\
\hline \multirow{6}{*}{ 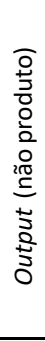 } & \multirow{2}{*}{$\begin{array}{l}\downarrow \text { Perda de matéria } \\
\text { prima por resíduo }\end{array}$} & $\begin{array}{c}\text { Tijolos de referência } \\
14 \times 19 \times 24 \mathrm{~cm} \\
\end{array}$ & $141^{* *}$ & pç & $\mathrm{R} \$ 0,96$ & $\mathrm{R} \$ 135,36$ & \multirow{2}{*}{$\begin{array}{c}\mathrm{R} \$ 135,36 \\
\text { (parcial) }\end{array}$} & \multirow{6}{*}{$\mathrm{R} \$ 135,36$} & \multirow{6}{*}{$3,7 \%$} \\
\hline & & $\begin{array}{c}\text { Argamassa } \\
\text { residual }\end{array}$ & $\begin{array}{c}\text { Não } \\
\text { contabilizada }\end{array}$ & $\mathrm{m}^{3}$ & $\mathrm{R} \$ 300,00$ & Indefinido & & & \\
\hline & \multirow{4}{*}{$\begin{array}{c}\downarrow \text { Resíduo } \\
\text { Classe "A" } \\
\text { (cascalho de tijolo, } \\
\text { particulados de tijolos } \\
\text { e argamassa residual) }\end{array}$} & $\begin{array}{c}\text { Tratamento e } \\
\text { armazenamento }\end{array}$ & 0,91 & $\mathrm{~m}^{3}$ & $\mathrm{R} \$ 0,00$ & $\mathrm{R} \$ 0,00$ & \multirow{4}{*}{ Indefinido } & & \\
\hline & & Destinação & 0,91 & $\mathrm{~m}^{3}$ & $\mathrm{R} \$ 0,00$ & $\mathrm{R} \$ 0,00$ & & & \\
\hline & & Multas & 0 & - & $\mathrm{R} \$ 0,00$ & $\mathrm{R} \$ 0,00$ & & & \\
\hline & & $\begin{array}{l}\text { Danos à imageme } \\
\text { reputação da empresa }\end{array}$ & 0,91 & $\mathrm{~m}^{3}$ & $\begin{array}{c}\text { Não } \\
\text { calculado }\end{array}$ & Indefinido & & & \\
\hline & & E & ção de dados & $\begin{array}{l}\mathrm{S} \text { finais de } \\
\text { ara custos }\end{array}$ & $\begin{array}{l}\text { ansformaçãc } \\
\text { nais de trans }\end{array}$ & $\begin{array}{l}\text { analisados en } \\
\text { ormação em } 1\end{array}$ & $\begin{array}{l}\text { pavimento tip } \\
\text { avimentos tip }\end{array}$ & $\begin{array}{l}\mathrm{R} \$ 3 . \\
\mathrm{R} \$ 40\end{array}$ & \\
\hline
\end{tabular}

* Referência: 1 pavimento tipo

** Quantidade relativa à parte dos cascalhos de tijolos segregados dos resíduos de um pavimento, excluindo os particulados de tijolos presentes na parte de resíduos misturados com argamassa residual que não puderem ser segregados.

Fonte: Autores (2016).

Por meio dos resultados obtidos, conclui-se que o output (não produto) representa um acréscimo de 3,7\% ao custo da atividade de elevação de alvenaria externa.

As perdas de particulados de tijolos e argamassa, de materiais por incorporação de argamassa à alvenaria e as sobras de argamassa lançadas para área externa quando do assentamento de tijolos cerâmicos não foram contabilizadas; a primeira por não ser possível a sua segregação com os recursos disponíveis, a segunda foi proposta para a equipe executora, porém as amostras coletadas não foram consideradas satisfatórias, a terceira, inviabilizada pela dificuldade de coleta de material impregnada à plataforma, tendo em vista que a argamassa residual de outros pavimentos somaram-se a estas, o que não 
traria um resultado real para o estudo. Outros fatores que poderiam aumentar os índices de perdas, seriam: a quantificação das perdas do processo logístico até o pavimento de trabalho e a realização da coleta de dados após a retirada dos tijolos inteiros que restaram no pavimento, com a conclusão da atividade de elevação de alvenaria, já que uma das causas das quebras são as movimentações.

Durante e após o período de acompanhamento da atividade de elevação de alvenaria externa, as deficiências observadas foram caracterizadas em possíveis fatores que poderiam gerar perdas de materiais e consumo desnecessário de recursos naturais, sob o ponto de vista dos aspectos operacionais, matéria-prima e recursos humanos, conforme segue:

Operacionais:

- Etapas desnecessárias no processo, observada na Erro! Fonte de referência não encontrada. (a), (b) e (c), provocada pela ausência de projeto/implementação de layout do canteiro de obra do pavimento de trabalho;

- Inexistência de indicador de perdas de materiais;

- Desconhecimento do consumo unitário de materiais, necessários para execução da atividade (produtividade dos materiais);

Matéria-prima:

- Uso de matéria-prima de qualidade inadequada, com geometria irregular, e apresentando falhas na fabricação, observado na Erro! Fonte de referência não encontrada. (d), (e) e (f);

- Descuidos na inspeção de qualidade quando do recebimento dos materiais, conforme estabelece a Instrução de Serviço existente;

- Uso de carrinhos inadequados para o transporte de tijolos, conforme Erro! Fonte de referência não encontrada. $(\mathrm{g})$;

-Armazenagem inadequada dos tijolos;

-Deficiência no suprimento.

Recursos humanos:

- Treinamento inadequado para a redução de perdas, por resíduos e incorporação conforme observados na Erro! Fonte de referência não encontrada. $(g)$ e (h);

-Acompanhamento técnico reduzido durante a execução do serviço. 


\section{ounisul sime}

Figura 5: Evidências da ocorrência de perdas na execução de alvenaria externa de tijolo cerâmico

(a) e (b) Pilhas de tijolos e formas de supra estrutura em locais inadequados, que dificultam na movimentação e transporte interno gerando possíveis quebras de tijolos

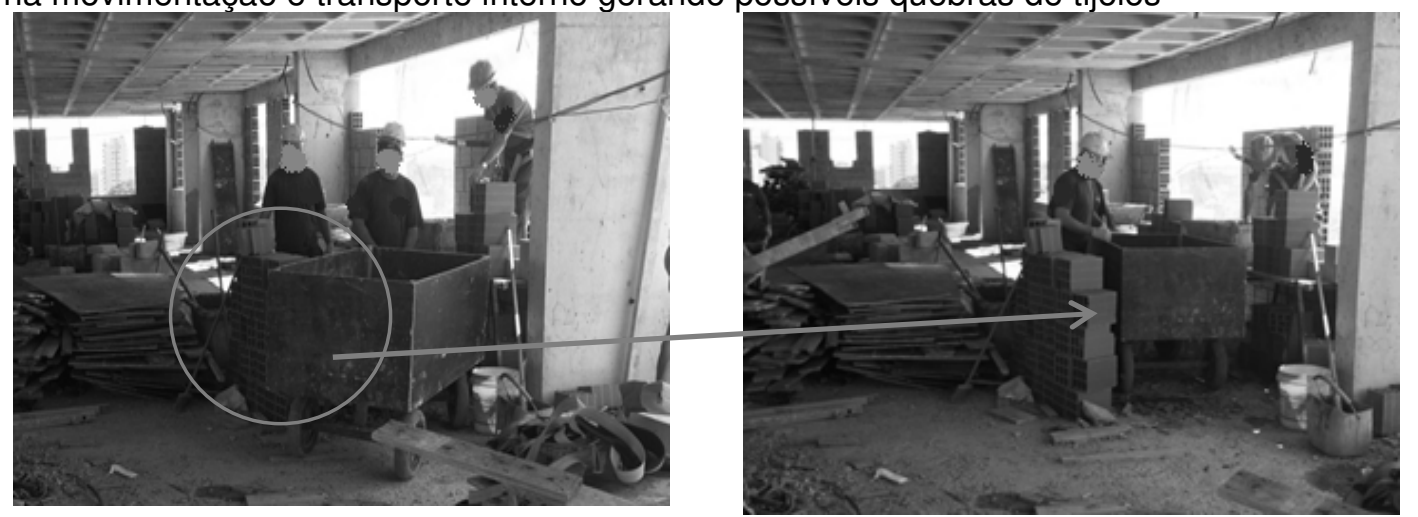

(c) Várias pilhas de tijolos desorganizadas e ainda misturadas com outros materiais

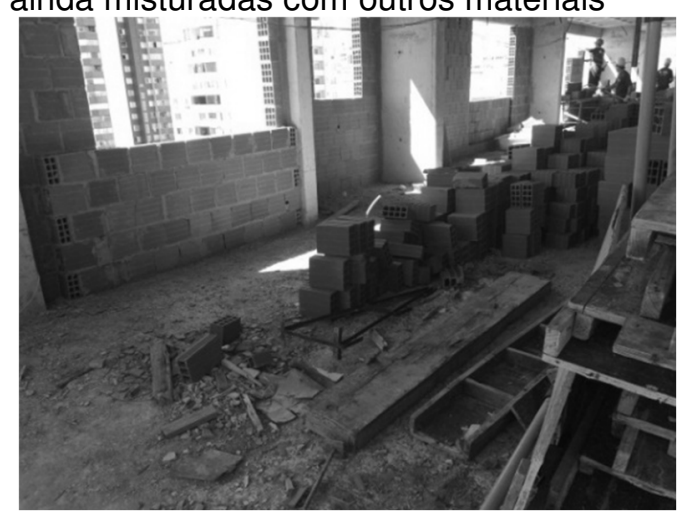

(d) Evidência da fragilidade dos tijolos nas pilhas

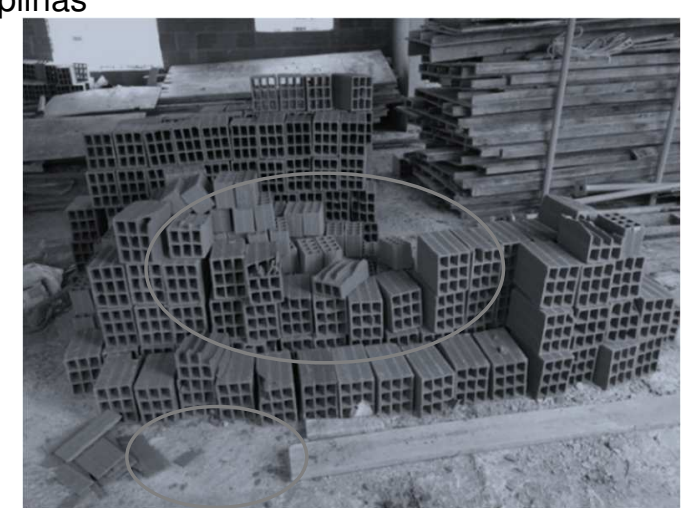

(e) Evidência da fragilidade do tijolo já assentado

(f) Geometria irregular do tijolo e qualidade inadequada 


\section{sunisul}

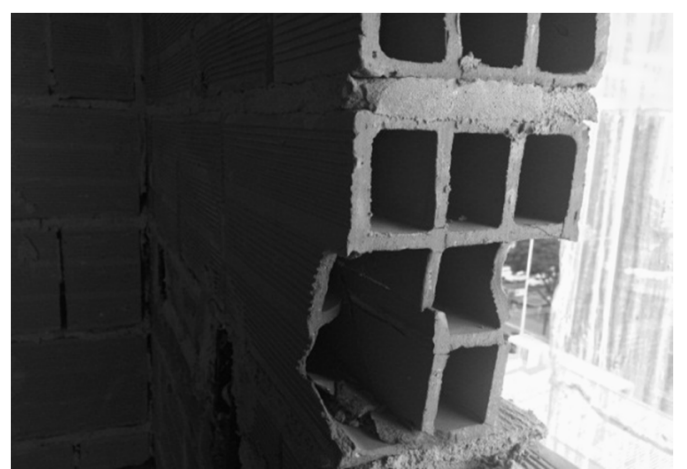

(g) Movimentação de tijolos no pavimento com transporte inadequado

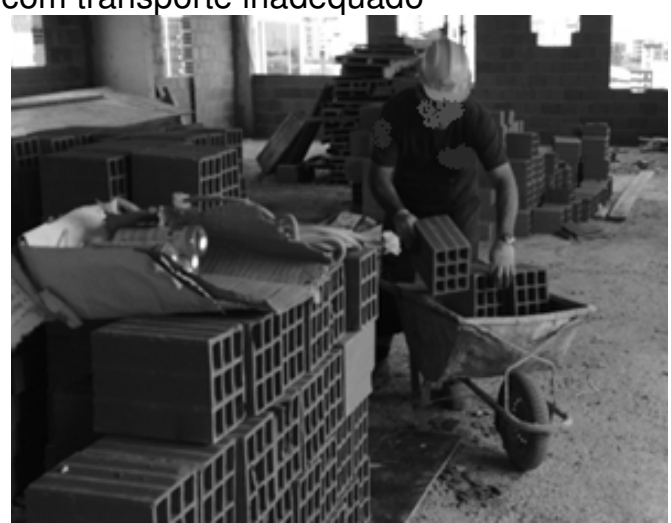

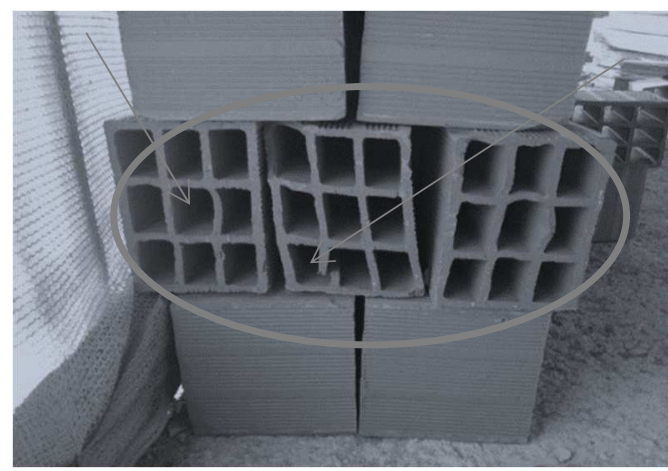

(h) Evidência de perda de argamassa incorporada à alvenaria

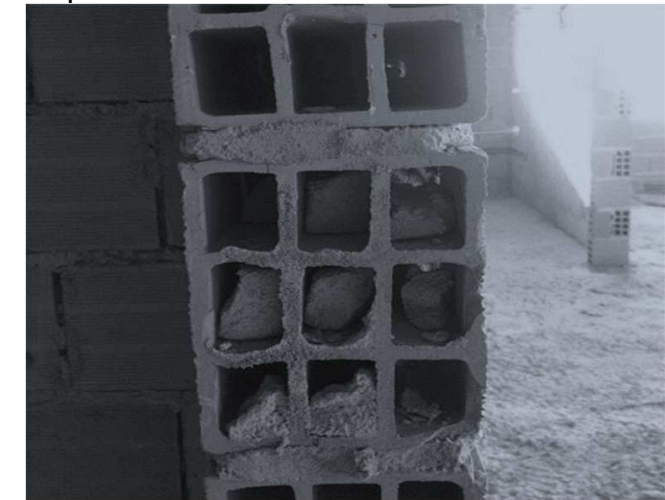

Fonte: Autores (2015).

Observa-se que a geração de resíduos contabilizados como saída na execução de alvenaria do pavimento em estudo, bem como as perdas por incorporação, poderia ser menor, caso os fatores listados fossem suprimidos por meio de um planejamento adequado de redução de perdas de materiais.

Assim propõe-se a redução na fonte pela modificação no processo, por meio de:

- Boas práticas operacionais:

i. Elaborar o layout do canteiro de obra (pavimento tipo), especificando onde devem ser alocado cada material e equipamento, e garantindo a mobilidade adequada e suficiente de pessoas e materiais para execução da atividade (o que eliminaria as compensações de argamassa pela ausência de determinadas dimensões de tijolos), e os requisitos de segurança necessários para a continuidade dos serviços.

ii. Fazer uso efetivo da instrução de serviço, principalmente nos itens que estão deixando a desejar, como no recebimento e aceitação de materiais.

iii. Treinamentos e capacitação de funcionários em $P+L$ nas atividades que julgarem-se prioritárias: formar funcionários em $\mathrm{P}+\mathrm{L}$, os quais serão responsáveis pela ampliação e 
desenvolvimento de estudos, implementações, continuidade e monitoramento de oportunidades de melhorias com a técnica.

- Substituição de matérias-primas:

iv. Substituição de fornecedor: caso o fornecedor atual seja reprovado nas próximas entregas, observada a fragilidade dos lotes de tijolos, sugere-se sua substituição por outros fornecedores de tijolos cerâmicos, que garantam qualidade, prazo e preço compatível. Obs.: A atenção adequada à instrução de serviço existente poderia viabilizar a manutenção do atual fornecedor, bastando que houvesse de fato o atendimento à questão sobre rejeição de recebimento de lotes de materiais de qualidade duvidosa.

- Modificação tecnológica:

v. Uma alternativa seria utilizar a bisnaga para aplicação de argamassa no assentamento dos tijolos, em substituição da colher de pedreiro. A ferramenta permite que a argamassa seja distribuída uniformemente e em formato de cordão, sem desperdícios, sobretudo os de incorporação nos furos dos tijolos.

vi. Outra alternativa para redução de desperdícios, é a utilização da colher meia cana para assentamento de tijolos com argamassa, em substituição da colher de pedreiro. Esta ferramenta permite que a argamassa seja coletada e aplicada uniformemente e em formato de cordão, sem desperdícios, sobretudo os de incorporação nos furos dos tijolos.
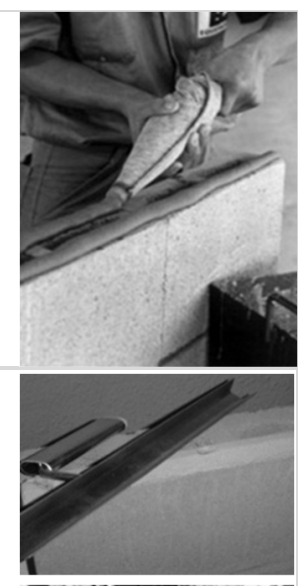

Para cada uma das oportunidades destacadas, foram revelados os gastos para suas implementações de acordo com o tempo de término de obra previsto e pavimentos que restavam elevar, conforme segue:

i. $\quad$ Estudo de layout do canteiro (pavimento tipo)

O custo mensal da empresa para contratação do técnico em edificações foi calculado na Equação Erro! Fonte de referência não encontrada., baseado no salário para cargos de técnico de nível médio praticado na Empresa, $\mathrm{R} \$ 1.917,00$, e dos índices de encargos 
de mensalista sem desoneração, 72,29\%, fornecido pelo Sistema Nacional de Pesquisas de Custos e Índices da Construção Civil - SINAPI.

Custo mensal do técnico para Empresa $=$ valor dos salários ${ }^{*}$ índices de encargos

Custo mensal do técnico para empresa $=R \$ 1.917,00+R \$ 1.917,00 * 72,29 \%$

Custo mensal do técnico para empresa $=\mathrm{R} \$ 3.302,80 /$ mês

Destaca-se que o técnico em edificações terá outras atribuições, e seu custo será dividido entre as outras 23 atividades desenvolvidas nos 4 pavimentos tipo à executar (do 12 ao 15), nos próximos 17 meses de obra (período que compreende o mês posterior no qual foi realizado o diagnóstico, junho de 2015, até a data prevista para conclusão da obra, outubro de 2016). Dessa forma, o custo para contratação do técnico em edificações é de $\mathrm{R} \$ 2.339,48$ por atividade do pavimento tipo.

ii. Uso efetivo da instrução de serviço existente

Os custos por atividade do pavimento tipo com a contratação de técnico em edificações, já foram discriminados na oportunidade "i". Dessa forma, caso se adote as oportunidades "i" e "ii", este custo deve ser dividido entre ambas, $\mathrm{R} \$ 1169,74$ para cada, já que trata-se da mesma atividade (elevação de alvenaria).

iii. Treinamento e capacitação de pessoas em Produção mais Limpa

Para capacitação dos ECOTIMES em Produção mais Limpa, o CNTL recomenda, em média, 5 encontros com duração total de $20 \mathrm{hs}$, além de palestras de sensibilização de curta duração para todos os colaboradores da empresa, que foi estimada em 5 hs. Além disso, foram consideradas despesas com viagens do especialista, nos trechos que compreendem Porto Alegre - Passo Fundo e Passo Fundo - Porto Alegre. Todos estes itens estão descritos no Quadro 2.

Quadro 2 - Custos envolvidos na contratação do especialista em $P+L$

\begin{tabular}{|c|c|}
\hline Descrição & Custo (R\$) \\
\hline Capacitação em P+L em 5 encontros (R\$ 132,00/hora, com estimativa de 25 horas ao todo) & $3.300,00$ \\
\hline Despesas de viagem, ônibus leito ( $\mathrm{R} \$ 110,85 /$ trecho, 10 trechos ao todo) & $1.108,50$ \\
\hline
\end{tabular}


Fonte: Autores (2016).

Como esta oportunidade não é restrita à atividade de elevação de alvenaria, seu custo pode ser dividido juntamente com as outras 23 atividades produtivas dos pavimentos tipo, se obtendo dessa forma, o custo final de $R \$ 183,69$ para cada uma das 24 atividades.

iv. Substituição de fornecedor de tijolos cerâmicos

Como a escolha do novo fornecedor depende da avaliação técnica da equipe de obra, não foi possível o levantamento de custo, por não estar definido até o presente momento. Ainda assim, sugere-se o cálculo da diferença de custo por peça, praticada entre os fornecedores atual e futuro.

v. Adoção de ferramentas que reduzam perdas (bisnaga)

Levando em consideração as informações do fabricante, o qual indica que uma bisnaga chega a assentar $130 \mathrm{~m}^{2}$ de alvenaria $(A A B)$ e que, a alvenaria externa de um pavimento tipo do Edifício em questão, possui área total em torno de $180 \mathrm{~m}^{2}$ (AT), com descontos de aberturas, 4 pavimentos que ainda faltam elevar (FE), conta-se com a mão de obra de 5 duplas de profissionais e serventes nesta atividade (DP), calcula-se que serão necessários 10 bisnagas, 2 para cada dupla, conforme demonstrado na Equação (1).

$$
\begin{gathered}
\text { Quantidade necessária por dupla }=\frac{\left(\frac{A T m^{2} x F E}{A A B m^{2}}\right)}{D P} \\
\text { Quantidade necessária por dupla }=\frac{\left(\frac{180 \mathrm{~m}^{2} x 4}{130 \mathrm{~m}^{2}}\right)}{5}=1,11, \\
\text { arredonda - se para } 2 \text { unidades. }
\end{gathered}
$$

Os custos envolvidos com a aquisição dessa ferramenta estão discriminados no Quadro 3.

Quadro 3 - Custos envolvidos na aquisição da bisnaga 
GESTÃO \& SUSTENTABILIDADE

AMBIENTAL

\section{unisul}

\section{$\equiv$}

Aquisição de bisnaga (cada pacote 6 unidades, a $\mathrm{R} \$ 88,00$ o pacote, adquirir 2 pacotes)

176,00

Frete

Total $(\mathrm{R} \$)$

176,00

Fonte: Autores (2016).

vi. Adoção de ferramentas que reduzam perdas (colher meia cana)

Como o quadro de funcionários da obra possui 5 duplas de pedreiros e serventes, sugere-se a aquisição inicial de 5 unidades de colher meia cana para teste, com o custo total de $\mathrm{R} \$ 136,00$, conforme demonstrado no Quadro 4.

Quadro 4 - Custos envolvidos na aquisição de colher meia cana

\begin{tabular}{|c|c|}
\hline Descrição & Custo (R\$) \\
\hline Colher meia cana (5 unidades, $\mathrm{R} \$ 34,00 /$ unidade) & 170,00 \\
\hline Total (R\$) & $\mathbf{1 7 0 , 0 0}$ \\
\hline
\end{tabular}

Fonte: Autores (2016).

Para auxiliar na implementação destas oportunidades, foi elaborado o Quadro 5, com auxílio da ferramenta de qualidade, 5W2H. As oportunidades de melhorias para não geração e, na impossibilidade, a redução de perdas de materiais destacadas na presente pesquisa objetivaram, em concordância com a priorização do sistema de gestão estabelecido no programa de Produção mais Limpa (CNTL, 2007b), bem como na Resolução CONAMA n 307 (BRASIL, 2002) e na Política Nacional de Resíduos Sólidos sob Lei Federal 12.305 (BRASIL, 2010), estratégias de redução na fonte. Não foram listadas opções de reuso e reciclagem, e atendendo à ordem estabelecida nesses documentos, da forma como foi proposto, entende-se que o benefício ao meio ambiente torna-se mais efetivo do que se tais opções fossem priorizadas. 
GESTÃO \& SUSTENTABILIDADE

AMBIENTAL

\section{ounisul}

Quadro 5 - Plano de implementação das oportunidades estudadas

\begin{tabular}{|c|c|c|c|c|c|c|}
\hline O que fazer? & Por que fazer? & Quem fará? & Onde fazer? & Quando fazer? & Como fazer? & Quanto custará? \\
\hline $\begin{array}{l}\text { i. Estudo de layout } \\
\text { do canteiro } \\
\text { (pavimento tipo) }\end{array}$ & $\begin{array}{l}\text { Para reduzir os } \\
\text { índices resíduos }\end{array}$ & $\begin{array}{l}\text { Equipe técnica de obra } \\
\text { fará (ou contratará) o } \\
\text { estudo do layout } \\
\text { adequado }\end{array}$ & Nos pavimentos tipo. & $\begin{array}{l}\text { Antes da execução } \\
\text { da elevação de } \\
\text { alvenaria externa de } \\
\text { cada pavimento }\end{array}$ & $\begin{array}{c}\text { Discriminar materiais e } \\
\text { objetos encontrados } \\
\text { atualmente no pavimento, } \\
\text { verificar sua necessidade de } \\
\text { permanência, bem como os } \\
\text { caminhos e as quantidades } \\
\text { suficientes } \\
\end{array}$ & $\begin{array}{l}\text { O custo desta oportunidade } \\
\text { é relativo à função de um } \\
\text { técnico em edificações, } R \$ \\
2339,48\end{array}$ \\
\hline $\begin{array}{l}\text { ii. Uso efetivo da } \\
\text { instrução de } \\
\text { serviço existente }\end{array}$ & $\begin{array}{l}\text { Para reduzir os } \\
\text { índices resíduos }\end{array}$ & $\begin{array}{l}\text { O técnico em edificações } \\
\text { será o responsável pelo } \\
\text { treinamento. Caso não } \\
\text { seja contratado, } \\
\text { recomenda-se o } \\
\text { engenheiro responsável } \\
\text { pela obra }\end{array}$ & $\begin{array}{c}\text { No refeitório da obra } \\
\text { (palestra), e nos locais } \\
\text { onde ocorram a atividade }\end{array}$ & $\begin{array}{l}\text { No máximo a cada } 6 \\
\text { meses, e sempre que } \\
\text { um novo funcionário } \\
\text { que trabalhará nessa } \\
\text { atividade, for } \\
\text { contratado }\end{array}$ & $\begin{array}{l}\text { Apresentar demonstrações } \\
\text { reais de como fazer, o que } \\
\text { não deve ser feito, e o que } \\
\text { não deve ser aceito; } \\
\text { apresentações de vídeos; } \\
\text { ouvir os trabalhadores, } \\
\text { quanto à sugestões e } \\
\text { queixas } \\
\end{array}$ & $\begin{array}{l}\text { O custo desta oportunidade } \\
\text { é relativo à função de um } \\
\text { técnico em edificações, } R \$ \\
2339,48\end{array}$ \\
\hline $\begin{array}{l}\text { iii. Treinamento e } \\
\text { capacitação de } \\
\text { pessoas em } \\
\text { Produção mais } \\
\text { Limpa }\end{array}$ & $\begin{array}{l}\text { Para capacitar } \\
\text { funcionários que } \\
\text { farão parte do } \\
\text { Ecotime }\end{array}$ & $\begin{array}{l}\text { O consultor do CNTL em } \\
\text { Produção mais Limpa }\end{array}$ & $\begin{array}{l}\text { Nas dependências da obra } \\
\text { (refeitório) }\end{array}$ & $\begin{array}{l}\text { A ser definido pela } \\
\text { construtora mediante } \\
\text { aprovação, e } \\
\text { disponibilidade do } \\
\text { especialista }\end{array}$ & $\begin{array}{l}\text { A ser definido pelo } \\
\text { especialista contratado }\end{array}$ & $\begin{array}{l}\text { O custo desta oportunidade } \\
\text { é relativa à contratação de } \\
\text { consultoria, } R \$ 183,69\end{array}$ \\
\hline $\begin{array}{l}\text { iv. Substituição de } \\
\text { fornecedor de } \\
\text { tijolos cerâmicos }\end{array}$ & $\begin{array}{l}\text { Para reduzir os } \\
\text { índices resíduos }\end{array}$ & $\begin{array}{c}\text { A equipe de engenharia } \\
\text { entrará em contato com } \\
\text { outros fornecedores de } \\
\text { tijolos cerâmicos da } \\
\text { região de Passo Fundo- } \\
\text { RS }\end{array}$ & $\begin{array}{l}\text { Os contatos e cadastros } \\
\text { serão realizados no } \\
\text { escritório da obra, e, caso } \\
\text { necessário, a equipe } \\
\text { técnica realizará visita nas } \\
\text { olarias dos potenciais } \\
\text { fornecedores }\end{array}$ & $\begin{array}{c}\text { Tão logo a proposta } \\
\text { seja aprovada pela } \\
\text { diretoria da } \\
\text { construtora }\end{array}$ & $\begin{array}{l}\text { Com respaldo técnico, } \\
\text { econômico e ambiental, } \\
\text { avaliar e substituir o atual } \\
\text { fornecedor de tijolos }\end{array}$ & $\begin{array}{l}\text { Indefinido, por não } \\
\text { conhecer os valores do } \\
\text { fornecedor que será } \\
\text { escolhido. }\end{array}$ \\
\hline $\begin{array}{l}\text { v. Adoção de } \\
\text { ferramentas que } \\
\text { reduzam perdas } \\
\text { (bisnaga) }\end{array}$ & $\begin{array}{l}\text { Para reduzir os } \\
\text { índices resíduos } \\
\text { de argamassa }\end{array}$ & $\begin{array}{l}\text { O setor de compras deve } \\
\text { efetuar a aquisição; já a } \\
\text { equipe técnica deverá } \\
\text { garantir o treinamento } \\
\text { dos pedreiros, que } \\
\text { utilizarão a bisnaga }\end{array}$ & $\begin{array}{c}\text { Pesquisa de custo e } \\
\text { aquisição, no escritório da } \\
\text { obra; já o uso da } \\
\text { ferramenta, no canteiro-de- } \\
\text { obra, durante a elevação } \\
\text { das alvenarias }\end{array}$ & $\begin{array}{c}\text { Tão logo a proposta } \\
\text { seja aprovada pela } \\
\text { diretoria da } \\
\text { construtora }\end{array}$ & $\begin{array}{c}\text { Utilizar bisnaga para } \\
\text { aplicação de argamassa no } \\
\text { assentamento dos tijolos, em } \\
\text { substituição da colher de } \\
\text { pedreiro }\end{array}$ & $\begin{array}{c}\text { A aquisição das bisnagas } \\
\text { geram um custo de } \mathrm{R} \$ \\
176,00, \text { para finalizar o } \\
\text { serviço dos } 4 \text { pavimentos } \\
\text { restantes }\end{array}$ \\
\hline
\end{tabular}

Revista Gestão e Sustentabilidade Ambiental., v. 10, n. 3, p. 24-55, set. 2021. 
GESTÃO \& SUSTENTABILIDADE

AMBIENTAL

\section{sunisul}

\begin{tabular}{|c|c|c|c|c|c|c|}
\hline O que fazer? & Por que fazer? & Quem fará? & Onde fazer? & Quando fazer? & Como fazer? & Quanto custará? \\
\hline $\begin{array}{l}\text { vi. Adoção de } \\
\text { ferramentas que } \\
\text { reduzam perdas } \\
\text { (colher meia cana) }\end{array}$ & $\begin{array}{l}\text { Para reduzir os } \\
\text { índices resíduos } \\
\text { de argamassa }\end{array}$ & $\begin{array}{c}\text { O setor de compras deve } \\
\text { efetuar a aquisição; já a } \\
\text { equipe técnica deverá } \\
\text { garantir o treinamento } \\
\text { dos pedreiros, que } \\
\text { utilizarão a colher meia } \\
\text { cana }\end{array}$ & $\begin{array}{c}\text { Pesquisa de custo e } \\
\text { aquisição, no escritório da } \\
\text { obra; já o uso da } \\
\text { ferramenta, no canteiro-de- } \\
\text { obra, durante a elevação } \\
\text { das alvenarias }\end{array}$ & $\begin{array}{l}\text { Tão logo a proposta } \\
\text { seja aprovada pela } \\
\text { diretoria da } \\
\text { construtora }\end{array}$ & $\begin{array}{l}\text { Utilizar colher meia cana } \\
\text { para assentamento de tijolos } \\
\text { com argamassa, em } \\
\text { substituição da colher de } \\
\text { pedreiro }\end{array}$ & $\begin{array}{c}\text { A aquisição das colheres } \\
\text { meia cana geram um custo } \\
\text { de } R \$ 170,00 \text {, para finalizar } \\
\text { o serviço dos } 4 \text { pavimentos } \\
\text { restantes }\end{array}$ \\
\hline
\end{tabular}


Quanto à metodologia de Produção mais Limpa utilizada na pesquisa e desenvolvida pelo CNTL (2007b), observou-se que a mesma abre espaço para diversas lacunas que podem causar diferentes interpretações. Por esse motivo outras fontes sobre a metodologia de $\mathrm{P}+\mathrm{L}$ foram consultadas para o desenvolvimento do trabalho, como as do CEBDS (2012), CNTL (2015), CNTL (2007a), CNTL (2003a) e CNTL (2003b) de forma a tentar suprir essa carência de informações mais objetivas. Uma fonte que contribuiu muito para a finalização deste trabalho foi a Silva et. al (2013), com suas observações e incrementos de ferramentas da qualidade nas etapas metodológicas de Produção mais Limpa. Outra fonte, adotada para somar nas fases de diagnóstico ambiental e de processo e no entendimento das perdas, foi a de Souza (2005), o qual indica métodos para identificação e coletas de dados.

Mesmo com o percentual encontrado nos levantamentos de dados atuais da atividade de elevação de alvenaria externa identificados na presente pesquisa, o qual considerou a relação entre o somatório de entradas (input) e saídas (output - não produto) de $3,7 \%$, Souza (2005) considera a redução de perdas de materiais na produção de edifícios extremamente desejável, tanto do ponto de vista da busca da sustentabilidade da construção quanto da competitividade das construtoras. Por esse motivo, se propôs oportunidades de melhoria para reduzir ainda mais a geração de resíduos e o consumo desnecessário de recursos naturais na forma de matéria-prima.

Durante a elaboração da pesquisa, foram levantadas outras opções além das apresentadas na fase de identificação das oportunidades de Produção mais Limpa, tanto para boas práticas operacionais (como solicitar ao atual fornecedor a paletização dos tijolos, por exemplo), bem como a substituição de matérias primas (tijolos cerâmicos por blocos de concreto celular, blocos de concreto e tijolos cerâmicos modulares e blocos que dispensam reboco). Contudo, a paletização no caso dessa obra específica, não seria possível em função de espaço e da logística dos materiais, conforme observado pelo engenheiro da obra. Já as substituições de matérias primas não foram consideradas viáveis no momento da pesquisa, já que impactariam em mudanças na fase de concepção (projeto), o que não é o objetivo deste trabalho.

Mas, para que esta prevenção de perdas ocorra, e seja possível estender o conhecimento em $\mathrm{P}+\mathrm{L}$ adquirido às outras atividades, é de fundamental importância que a sensibilização e comprometimento da alta administração com tais práticas ocorram. Para Andrade e Souza (2000), estando a empresa envolvida e comprometida com a gestão do 
canteiro, os responsáveis pela coleta se sentirão motivados para realização dos serviços, e que a motivação aumenta à medida que os resultados começam a surgir. Para Marques e colaboradores (2017) o comprometimento da direção da empresa com a eficiência no uso dos recursos na obra é imprescindível, sendo este o ponto inicial e talvez crucial para a implementação de ações de melhoria, uma vez que estas envolvem investimentos, desde um projeto racional, uso de tecnologias e materiais economizadores, alocação da mão de obra para manutenção e inspeção, e desenvolvimento dos colaboradores.

Dentre os principais benefícios com a possível implementação das oportunidades evidenciadas na pesquisa, destaca-se: as ambientais, de modo que se reduzirá a geração de resíduos, logo os recursos materiais deverão ser eficientemente transportados, armazenados e empregados no produto, que é o edifício em construção, além da redução do transporte e destinação de resíduos, que nesta obra não gera implicações externas, contudo geralmente ocorrem em outras obras de mesma tipologia; e econômicas, com a redução de custos em relação à quantidade de matéria-prima adquirida, e dos retrabalhos, antes do conhecimento do caminho das perdas e com a possível implementação das oportunidades de melhoria.

Os resultados obtidos na pesquisa foram apresentados aos representantes da Obra e Empresa, (Engenheiro responsável pela obra e Engenheiro responsável pelo setor de Qualidade), bem como para um Engenheiro Civil da cidade, com larga experiência em canteiros de obra de edifícios multipavimentos - sem vínculo com a Empresa da obra em estudo. $O$ intuito desta apresentação foi extrair suas percepções e avaliações em relação aos resultados apresentados na etapa 3 , com as oportunidades de melhoria na elevação de alvenaria externa. As observações realizadas por eles foram apresentadas no Quadro 6.

Por fim, os representantes da Empresa consideram as sugestões bastante pertinentes, com possibilidades de aplicação e adaptação à realidade da empresa, com as ressalvas descritas no Quadro 6 e que, dentre todas as sugestões, a primeira seria a mais interessante para implementação. 
Quadro 6 - Observações de representantes da Empresa e Engenheiro experiente, com relação às oportunidades apresentadas na pesquisa

\begin{tabular}{|c|c|}
\hline Oportunidade & ções \\
\hline \multirow[t]{2}{*}{$\begin{array}{l}\text { I. Estudo de } \\
\text { layout do } \\
\text { canteiro }\end{array}$} & $\begin{array}{l}\text { Consideram a oportunidade mais interessante. Um planejamento de } \\
\text { layout do canteiro é algo que já foi pensado, mas nunca posto em } \\
\text { prática, e que realmente traria vários benefícios para a obra em } \\
\text { diferentes aspectos, não somente com relação aos custos diretos, } \\
\text { mas também nos indiretos, quando se trata de agilidade dos } \\
\text { serviços, economia de tempo e prazo de obra. }\end{array}$ \\
\hline & $\begin{array}{l}\text { Muito oportuno e com custo de implantação baixo, comparado com c } \\
2 \text { desperdício que gera a falta de planejamento no canteiro referente a } \\
\text { este item. }\end{array}$ \\
\hline \multirow[t]{2}{*}{$\begin{array}{c}\text { II. Uso } \\
\text { efetivo da } \\
\text { instrução de } \\
\text { serviço } \\
\text { existente }\end{array}$} & $\begin{array}{l}\text { É fato que a correta utilização das instruções de trabalho melhoraria } \\
\text { a qualidade dos serviços, bem como dos processos aos quais estes } \\
\text { fazem parte, a dificuldade a nosso ver, está na questão do } \\
\text { treinamento e capacitação dos colaboradores; afinal conseguir } \\
\text { resultados satisfatórios requer grande esforço e persistência, uma } \\
\text { vez que mudar a mentalidade dos colaboradores não é tarefa fácil. } \\
\text { Em virtude da realidade a qual estamos passando no cenário da } \\
\text { economia e mercado de trabalho, talvez esta alternativa se torne } \\
\text { bastante pertinente, já que se percebe cada vez mais a "sobra" de } \\
\text { pessoas não qualificadas no mercado, podendo a construtora } \\
\text { "escolher" melhor os seus profissionais. Nessa perspectiva, quem } \\
\text { sabe então se criar critérios de contratação mais rígidos, a fim de } \\
\text { selecionar-se melhor a mão de obra. }\end{array}$ \\
\hline & $\begin{array}{l}\text { Aspecto importante que deve ser cumprido na integra, uma vez que } \\
2 \text { as instruções de serviço são estudadas e revisadas de forma a } \\
\text { buscar melhor qualidade do serviço e menor custo de produção. }\end{array}$ \\
\hline $\begin{array}{l}\text { III. } \\
\text { Treinamento } \\
\text { e }\end{array}$ & $\begin{array}{l}\text { É uma alternativa a se pensar, no ponto de vista de capacitar os } \\
\text { colaboradores que já fazem parte da empresa. Ao nosso ponto de } \\
\text { vista, a direção da empresa, talvez não esteja disposta a investir }\end{array}$ \\
\hline
\end{tabular}




\section{GESTÃO \& SUSTENTABILIDADE}

AMBIENTAL

\section{১unisul}

\begin{tabular}{|c|c|}
\hline Oportunidade & Observações \\
\hline \multirow[t]{2}{*}{$\begin{array}{l}\text { capacitação } \\
\text { de pessoas } \\
\text { em } \mathrm{P}+\mathrm{L}\end{array}$} & $\begin{array}{l}\text { nisto no atual momento. Talvez, capacitar um engenheiro da própria } \\
\text { empresa, para este então ficar responsável por disseminar esta } \\
\text { cultura da P+L pela empresa, neste caso talvez fique mais fácil uma } \\
\text { aceitação por parte da alta direção. }\end{array}$ \\
\hline & Treinamento é primordial pa \\
\hline \multirow[t]{2}{*}{$\begin{array}{c}\text { IV. } \\
\text { Substituição } \\
\text { de } \\
\text { fornecedor } \\
\text { de tijolos } \\
\text { cerâmicos }\end{array}$} & $\begin{array}{l}\text { Em virtude das novas exigências por parte da norma de } \\
\text { desempenho, foi necessário a utilização de novas tecnologias e } \\
\text { técnicas construtivas. Em outra obra, que começou após a obra em } \\
\text { estudo, já estão sendo utilizados blocos de outro fornecedor, sendo } \\
\text { estes de qualidade muito superior, e também atendendo às } \\
\text { especificações de conforto térmico e acústico, além da empresa } \\
\text { fornecer laudos e possuir controle de qualidade. Neste momento } \\
\text { também levanta-se a hipótese de inicia a elaboração de projetos de } \\
\text { modulação de alvenarias com a utilização de blocos modulares. }\end{array}$ \\
\hline & $\begin{array}{c}\text { Os blocos cerâmicos devem ser de boa qualidade devendo ser } \\
2 \text { inspecionados no recebimento e rejeitados os lotes fora dos limites } \\
\text { estabelecidos nas instruções de recebimento de materiais. }\end{array}$ \\
\hline \multirow{2}{*}{$\begin{array}{l}\text { V. Adoção de } \\
\text { ferramentas } \\
\text { que reduzam } \\
\text { perdas } \\
\text { (bisnaga) }\end{array}$} & $\begin{array}{c}\text { É uma boa recomendação a utilização da bisnaga e/ou colher meia } \\
\text { cana para a redução do desperdício na obra. Sendo que seria } \\
\text { necessário apenas a insistência em treinamento para os } \\
\text { funcionários. }\end{array}$ \\
\hline & $\begin{array}{l}\text { Não é recomendável a adoção de ferramentas como a bisnaga, por } \\
\text { causar Lesão por Esforço Repetitivo (LER), devido a força que o } \\
\text { profissional faz para tirar a argamassa }\end{array}$ \\
\hline \multirow{2}{*}{$\begin{array}{l}\text { VI. Adoção } \\
\text { de } \\
\text { ferramentas } \\
\text { que reduzam } \\
\text { perdas }\end{array}$} & $\begin{array}{c}\text { É uma boa recomendação a utilização da bisnaga e/ou colher meia } \\
\text { cana para a redução do desperdício na obra. Sendo que seria } \\
\text { necessário apenas a insistência em treinamento para os } \\
\text { funcionários. }\end{array}$ \\
\hline & 2 A adoçâ \\
\hline
\end{tabular}




\begin{tabular}{|c|c|}
\hline $\begin{array}{c}\text { Oportunidade } \\
\text { cana) }\end{array}$ & Observações \\
\hline colher meia & \\
\hline
\end{tabular}

1 - Respostas da Engenharia da Empresa

2 - Respostas do Engenheiro sem vínculo com a Empresa

Fonte: Autores (2016).

Conforme pode-se verificar, existem muitos benefícios com a implementação da Produção mais Limpa na construção civil, objetivando principalmente implementar princípios básicos a para uma construção sustentável, que consistem em ações de redução e otimização do consumo de materiais e energia, redução dos resíduos gerados, redução do consumo de água, aproveitamento das condições naturais locais, preservação do ambiente natural e melhoria da qualidade do ambiente construído. Farias (2010) recomenda a implementação de métodos e ações passivas, processos construtivos rigorosos e detalhados, seleção e utilização de materiais mais ecológicos e também avaliação e monitoramento contínuos. Além disso, para Baptista Junior e Romanel (2013), o sucesso da proposta depende da efetiva participação de todos os agentes envolvidos no processo.

\section{5- CONCLUSÕES}

Buscou-se relações de causas e efeitos para proporcionar a proximidade da solução dos problemas evidenciados relacionados com questões operacionais, matéria-prima e recursos humanos.

As principais matérias-primas das atividades eleitas para o estudo de caso, argamassa e tijolo cerâmico, são apontadas na literatura mundial como duas das grandes geradoras de resíduos na construção civil. Fato este, confirmado também em pesquisas locais recentes, que demonstram que as construções na cidade de Passo Fundo-RS, fazem parte desse contexto de geração. Sendo assim, o presente trabalho procurou trazer contribuições para o setor, por meio da redução de aquisições de materiais em quantidade e custos totais.

Para a identificação de oportunidades de melhoria, com avaliações e elaboração de um plano de implementação objetivando a redução de resíduos nos processos produtivos de edificações, foi necessário o estudo de suas causas e a busca por oportunidades que 
se adequassem ao canteiro de obra em estudo, mas que também pudesse servir de referência para outros canteiros semelhantes. As opções de melhoria apresentadas revelam que para reduzir perdas, não são necessários altos investimentos, bastando adaptações pontuais nos serviços já consolidados, e, por requerer investimentos de baixo custo, acredita-se que a implementação das proposições de melhoria torna-se viável a qualquer canteiro de obra semelhante ao estudado.

O plano de implementação proposto, incluindo meta de redução, acredita-se ser um bom ponto de partida e monitoramento para minimização dos resíduos no canteiro, inclusive porque a metodologia proposta pode ser aplicada não só em outras obras, mas em outras atividades produtivas dos canteiros, dada sua possibilidade de adaptação. Além disso, observa-se que esta proposta pode levar naturalmente à melhoria contínua, com rotina orientada para aumentar o grau de utilização das matérias-primas, com vantagens técnicas e econômicas, além de potencializar a transformação em produto, de insumos, energia e mão de obra utilizada, garantindo processos mais eficientes.

Com relação às análises dos representantes da Obra e Empresa, e do Engenheiro Civil sem vínculo com a construtora em questão, observa-se que, com exceção da restrição de uso da bisnaga (oportunidade V), sinalizada por questões ergonômicas e a contratação do consultor em P+L (oportunidade III), pelos gastos envolvidos ao trazê-lo para as instalações da Obra, muito embora não se descarte a possibilidade de enviar um funcionário para treinamento externo, todas as outras são pertinentes e passíveis de implementação, sendo uma já estudada para inclusão, como o estudo de layout do canteiro (oportunidade I) e outra já inserida em outra obra da Empresa, substituição de fornecedor de tijolos cerâmicos (oportunidade IV).

Espera-se com este trabalho, que esses e outros benefícios também possam fazer parte dos resultados obtidos na empresa em estudo e daquelas as quais o consultarem, incluindo os benefícios estratégicos com a implementação de medidas que maximizam resultados e minimizam impactos ambientais.

Por fim, sugere-se algumas propostas para pesquisas futuras, que possam contribuir com o desenvolvimento do tema: Implementação das oportunidades destacadas (realização de testes e avaliações); Quantificação de resíduos do processo logístico até o pavimento de trabalho; Estudo das perdas de materiais e mão de obra em edificações, conforme metodologia específica; Avaliação do impacto do ciclo de vida (AICV) para os 
materiais comumente utilizados em construções dessa tipologia; Correlação com a implementação de $\mathrm{P}+\mathrm{L}$ e atendimento dos requisitos da certificação LEED, referente à resíduos sólidos.

\section{REFERÊNCIAS}

BAPTISTA JUNIOR, J. V.; ROMANEL, C. Sustentabilidade na indústria da construção: uma logística para reciclagem dos resíduos de pequenas obras. Revista Brasileira de Gestão Urbana (Brazilian Journal of Urban Management), v. 5, n. 2, p. 27-37, jul./dez. 2013.

BERNARDES, A. et al. Quantificação e classificação dos resíduos da construção e demolição na cidade de Passo Fundo. Ambiente Construído, v. 8, n. 3, p. 65-76, 2008.

BRASIL. Ministério do Meio Ambiente. Conselho Nacional do Meio Ambiente. Resolução no 307, de 05 de julho de 2002. Alterada pelas Resoluções $n \div$ 348, de 2004, n 431, de 2011 e no 448, de 2012. Dispõe sobre gestão dos Resíduos da Construção Civil. Brasília, 2002. Disponível em: < www.mma.gov.br>. Acesso em: 15 out. 2014.

Produção mais Limpa em edificações. Porto Alegre: SENAI-RS, 88 P.

Presidência da República. Casa Civil. Lei no 12.305, de 02 de agosto de 2010. Institui a Política Nacional de Resíduos Sólidos - PNRS; altera a Lei no 9.605, de 12 de fevereiro de 1998; e dá outras providências. Brasília, 2010. Disponível em: < http://www.planalto.gov.br/ccivil_03/_ato2007-2010/2010/lei/l12305.htm>. Acesso em: 15 out. 2014.

Ministério do Meio Ambiente. Planos de gestão de resíduos sólidos: manual de orientação. 2012. 157 p. ICLEI-Brasil. Brasília, 2012.

BUTTLER, A. M. Uso de agregados reciclados de concreto em blocos de alvenaria estrutural. São Carlos. Tese (Doutorado) - Escola de Engenharia de São Carlos da Universidade de São Paulo. 499 p, 2007.

CARDOSO, F. F.; ARAUJO, V. M. Canteiros de Obras. In: PROJETO Tecnologias para Construção Habitacional Mais Sustentável: estado da arte. São Paulo: Edusp, 2006.

CBIC - CÂMARA BRASILEIRA DA INDÚSTRIA DA CONSTRUÇÃO. Construção civil é a locomotiva do crescimento, com emprego e renda. 2020. Disponível em:

https://cbic.org.br/construcao-civil-e-a-locomotiva-do-crescimento-com-emprego-e-renda/. Acesso em: jul. 2021.

CENTRO NACIONAL DE TECNOLOGIAS LIMPAS - CNTL. Cinco fases da implantação de técnicas de Produção mais Limpa. Porto Alegre: SENAI-RS, 2003a. 95 P. 
CNTL . Questões Ambientais e Produção mais Limpa. Porto Alegre: SENAI$\overline{\mathrm{RS} .126} \mathrm{p}, 2003 \mathrm{~b}$.

CNTL. Implementação de programas de produção mais Limpa. Porto Alegre: SENAI-RS.46p, $2007 a$. $2007 \mathrm{~b}$.

CNTL . Produção mais Limpa em edificações. Porto Alegre: SENAI-RS.88p,

. CNTL. Informações sobre Produção mais Limpa em edificações [mensagem pessoal]. Mensagem recebida por jbgularte@hotmail.com em 15 jun. 2015.

CONSELHO EMPRESARIAL BRASILEIRO PARA O DESENVOLVIMENTO SUSTENTÁVEL - CEBDS. Guia da Produção mais Limpa faça você mesmo. Rio de Janeiro: CEBDS, 2010.

DIAS, F. S. Etapas e Procedimentos nos Canteiros de Obras e Suas Influências no Desperdício na Construção Civil. Dissertação (Mestrado em Engenharia Civil) Universidade Estadual do Norte Fluminense, Campo dos Goitacazes, 2006.

FARIAS, P. M. A. Construção Sustentável: contributo para o processo de construção na alteração de uso nos Edifícios. Dissertação (Mestrado em Engenharia Civil) Faculdade de Ciências e Tecnologia, Universidade Nova de Lisboa, Lisboa, 2010.

GIL, A. C. Métodos e técnicas de pesquisa social. 6 ed. São Paulo: Atlas, 2008. 220 p.

JOHN, V. M.; AGOPYAN, V. (2008). Reciclagem de resíduos na construção. In:

Seminário de resíduos sólidos domiciliares, São Paulo. Disponível em: <www.reciclagem.pcc.usp.br>. Acesso em: out. 2014.

MACHADO, F. M. Gestão Sustentável: o gerenciamento dos resíduos sólidos da construção civil. Dissertação (Mestrado de Engenharia Civil) - Escola de Engenharia, Universidade Federal Fluminense, Rio de Janeiro, 2006.

MARKUSSON, N. Unpacking the black box of cleaner technology. Journal of Cleaner Production, v. 19, p. 294-302, 2011.

MARQUES, C. T; GOMES, B. M. F; BRANDLI, L. L. Consumo de água e energia em canteiros de obra: um estudo de caso do diagnóstico a ações visando à sustentabilidade. Ambiente Construído, Porto Alegre, v. 17, n. 4, p. 79-90, out./dez. 2017.

MARSHALL JUNIOR, I. et al. Gestão da Qualidade. Edição 9. Rio de Janeiro: Fundação Getúlio Vargas, 2010.

PASSO FUNDO. Lei no 4969 de 03 de janeiro de 2013. Institui a Política Municipal de Resíduos Sólidos de Passo Fundo e dá outras providências. 2013. Disponível em: <http://pmpf.rs.gov.br/index.php?p=1145\&a=1\&pm=1\&ifr=1 >. Acesso em nov. 2014. 
Lei no $\mathbf{5 1 0 2}$ de 05 de dezembro de 2014. Dispõe sobre o aproveitamento, reciclagem e processamento de entulho e estabelece diretrizes para o gerenciamento de resíduos oriundos da construção civil no município de Passo Fundo, conforme especifica. 2013. Disponível em: <http://pmpf.rs.gov.br/index.php?p=1145\&a=1\&pm=1\&ifr=1>. Acesso em nov. 2014.

PINTO, T. P.; GONZALES, J. L. R. Manejo e gestão de resíduos da construção civil. Manual de orientação 1. Como implantar um sistema de manejo e gestão dos resíduos da construção civil nos municípios. Brasília: CAIXA. 2013

RIO GRANDE DO SUL. Assembleia Legislativa. Legislações estaduais. Lei no 14528, de 16 de abril de 2014. Instituo a Política Estadual de Resíduos Sólidos e dá outras providências. 2014. Disponível em: <http://www.al.rs.gov.br/legislativo/>. Acesso em 15 mar. 2015.

SEVERO, E. M. F. Sustentabilidade nas Edificações Residenciais no Brasil. PTI Projeto de Tese de Investigação apresentado ao PRODEC-Programa Doutoral de Engenharia Civil da FEUP- Faculdade de Engenharia da Universidade do Porto, Portugal, 2013.

SANTOS, A.; FORMOSO, C. T.; ISATTO, E. L.; LANTELME, E. Método de intervenção para redução de perdas na construção civil: manual de utilização. Porto Alegre: SEBRAE/RS. 103 p, 1996.

SILVA, D. A. L.; DELAI, I.; CASTRO, M.A.S.; OMETTO, A. R. Quality tools applied to Cleaner Production porgrams: a first approach toward a new methodology. Journal of Cleaner Production. v. 47, p. 174-187, 2013.

SOBARZO, O. Passo Fundo: cidade média com funções comerciais, de serviço e de apoio ao agronegócio. In: SPOSITO, Maria Encarnação B.; ELIAS, Denise, SOARES, Beatriz R. (Org.). Agentes econômicos e reestruturação urbana e regional: Passo Fundo e Mossoró. São Paulo: Expressão Popular, p. 31-100,2010.

SOUZA, U. E. L. Como reduzir perdas nos canteiros: manual de gestão do consumo de materiais na construção civil. São Paulo: Pini Ltda, 128 p, 2005.

SU, X.; ANDOH, A. R.; CAI, H., PAN, J.; KANDIL, A; SAID, H. M. GIS-based dynamic construction site material layout evaluation for building renovation projects. Automation in construction, v. 27, p. 40-49, 2012.

SUZER, O. A comparative review of environmental concern prioritization: LEED vs other major certification systems. Journal of Environmental Management, v. 154, p. 266-283, 2015

UNEP. International declaration on cleaner production. Paris, 1998. Disponível em: <http://www.unep.fr/scp/cp/network/pdf/english.pdf>. Acesso em: 16 nov. 2017. 


\section{sunisul}

UNIDO/ UNEP. Manual de avaliação de $\mathbf{P + L}$, traduzido por CNTL/SENAI. Porto Alegre. 1995.

WU, Z.; YU, A. T; SHEN, L; L, G. Quantifying construction and demolition waste: An analytical review. Waste Management, v. 34, edição 9, p. 1692-1683, 2014.

YIN, R. K. Estudo de caso: planejamento e métodos. 2aㅗ ed. Porto Alegre: Bookman, 2001. 